\title{
Effect of Dentin Pretreatment with Arginine on Microshear Bond Strength of Etch-and-Rinse or Self-Etch Adhesive Systems
}

\author{
Gabriela Oliveira Borgo ${ }^{1}$ Waldemir Francisco Vieira-Junior ${ }^{1,2,3}$ Jéssica Dias Theobaldo ${ }^{1,3}$ \\ Flávio Henrique Baggio Aguiar ${ }^{1}$ Débora Alves Nunes Leite Lima ${ }^{1}$
}

\footnotetext{
${ }^{1}$ Department of Restorative Dentistry, Piracicaba Dental School, University of Campinas, Piracicaba, São Paulo, Brazil

2Department of Restorative Dentistry, São Leopoldo Mandic Institute and Dental Research Center, Campinas, São Paulo, Brazil

${ }^{3}$ School of Health Sciences, Centro Universitário das Faculdades

Metropolitanas Unidas, São Paulo, Brazil
}

Eur J Dent 2019;13:199-205

\begin{abstract}
Address for correspondence Waldemir Francisco Vieira-Junior, DDS, MSc, PhD, Faculdade e Centro de Pesquisas São Leopoldo Mandic, Rua José Rocha Junqueira, 13 - CEP 13045-755, Campinas,SP, Brazil (e-mail: waldemir.f@hotmail.com).
\end{abstract}

\begin{abstract}
Keywords

- arginine

- dentin

- adhesive systems

- adhesion

- dentin-bonding agents

Objective The main purpose of this study was to evaluate the effect of dentin pretreatment with $8 \%$ arginine on the immediate and 6 -month bond strength (BS) of adhesive systems and surface morphology of dentin.

Materials and Methods Dentin bovine specimens $(5 \times 5 \mathrm{~mm})$ were allocated into following pretreatments: without pretreatment (conventional technique, $\mathrm{C}$ ) or exposure to arginine solution (A) for 5 minutes prior to tooth restoration. The adhesive procedure was performed using $(n=12)$ : 3 -step etch-and-rinse adhesive (Scotchbond Multipurpose-SBMP [C+SBMP and A+SBMP]); 2-step etch-and-rinse adhesive (Single Bond 2 - SB [C+SB and A+SB]); or 2-step self-etch adhesive (Clearfil SE Bond - CSEB $[C+C S E B$ and $A+C S E B])$. After 24 hours, the composite resin restorations were evaluated immediately and after 6 months of water storage using a microshear test and fracture pattern. The dentin surface exposed to $A$ was assessed by scanning electron microscopy (SEM). The immediate BS data were submitted to a two-way analysis of variance and Tukey's test, and the long-term BS results were analyzed using KruskalWallis and Dunn tests $(\alpha=0.05)$.

Results There was a significant decrease in immediate and 6-month BS for the A+SB and $A+C S E B$ groups, which differed statistically from the $C$ group. The fracture pattern was predominantly adhesive for SB and CSEB adhesive for $C$ and A. The SEM images presented a different conditioning pattern of the dentin exposed to $A$.

Conclusion The dentin pretreatment with arginine interfered negatively in the immediate and long-term BS of the simplified adhesive system. However, the SBMP adhesive was not affected by arginine pretreatment presenting the most satisfactory results.
\end{abstract}

\section{Introduction}

Nowadays, one of the biggest concerns related to direct composite restorations is the longevity of adhesion between the resin-based materials and dental structures. ${ }^{1}$ Dental adhesion is a complex phenomenon related to the characteristics of hard tissue substrates, especially the dentin that mediated the development of different adhesive systems over time. The effectiveness of these adhesive systems can be compromised by degradation, caused by factors, such as 
absorption of the water present in the enamel and dentin ${ }^{2,3}$; microleakage of the restoration ${ }^{4,5}$; and activation of dentin metalloproteinases. ${ }^{1}$

Matrix metalloproteinases (MMPs) are proteolytic enzymes capable of degrading proteins of the dentin extracellular matrix, and its activation depends on several factors, ${ }^{1,6}$ such as the presence of proteinases or nonproteolytic agents during the restorative process. ${ }^{1,6}$ The odontoblasts are responsible for synthesizing the MMPs, which act in odontogenesis, the progression of dental caries, ${ }^{7,8}$ and the organization and mineralization of the dentin matrix. ${ }^{8}$ On the other hand, the MMPs are responsible for degrading the type I collagen fibrils ${ }^{9-11}$ that can be noninfiltrated by adhesive systems, ${ }^{12,13}$ affecting the longevity of restorations. ${ }^{14,15}$ To inhibit the MMP activation, some active principles have been proposed to decrease the proteolytic or collagenolytic activity, such as nonprotein thiols, ${ }^{16}$ galardin, ${ }^{17}$ and chlorhexidine. ${ }^{18}$

Considering the clinical variables that could affect the dental adhesion, previous studies ${ }^{19-21}$ evaluated the interference effect of desensitizing agents or products containing $8 \%$ arginine and calcium carbonate (Pro-Argin Technology; Colgate-Palmolive) on the bond strength (BS) of restorations. Arginine is an essential amino acid stable in aqueous solution, ${ }^{22}$ with an alkaline $\mathrm{pH}$ that enables the physical occlusion of the dentin tubules due to the deposition and precipitation of calcium and phosphate, decreasing the relief of dentin hypersensitivity. ${ }^{23,24}$ Moreover, the arginine could promote tooth protection against mineral loss and act on reversing erosive/demineralize processes. ${ }^{25,26}$

Pei et $\mathrm{al}^{19}$ suggested that adhesive systems are capable of interacting with the calcium creating an additional micromechanical bond and occluding the dentinal tubules through the formation of salts. The effects of the arginine alone in the dentin to be restored are unknown, and because this amino acid has high affinity with the collagen fibrils, the potential effects on the adhesion and the functions of MMPs must be explored. The objective of this study was to evaluate the effect of dentin pretreatment with $8 \%$ arginine on the immediate and 6-month BS of different adhesive systems and to assess the surface morphology of the substrate exposed to arginine. The null hypothesis of this study was that the arginine would not affect the adhesion process of different adhesives at different times of distilled water storage.

\section{Materials and Methods}

\section{Specimen Preparation}

One-hundred and forty-four fresh bovine teeth were cleaned and stored in $0.1 \%$ thymol-buffered solution. The dental bovine crown was separated from the root with a double-faced diamond disc (KG Sorensen, Ind. Com. Ltda, Barueri, Brazil) under constant irrigation. Specimens were obtained from the middle third of the buccal surface using a low-speed water-cooled diamond saw (Arotec, Cotia, Brazil). The blocks were embedded in polystyrene resin (Piraglass, Piracicaba, Brazil), with the exception of enamel surface. Afterward, the enamel was removed using 600-grit SiC papers (3M, Sumaré, Brazil) to expose the dentin. After the exposure of dentin, the dental fragments were cleaned in an ultrasonic machine for 15 minutes (Marconi; Piracicaba, Brazil) to remove residual particles. The smear layer standardization was performed with 600-grit SiC papers for 30 second. In the middle third of these blocks, a dentin area was delimited with acid-resistant varnish (Risque; Taboão da Serra, Brazil) to perform the microshear strength test $(5 \times 5 \mathrm{~mm})$ and capture the scanning electron microscopy $(\mathrm{SEM})$ images $(1 \times 3 \mathrm{~mm})$.

\section{Dentin Pretreatment with Arginine}

The solution of arginine was prepared from L-arginine powder (Dinâmica; Indaiatuba, Brazil) using deionized water, at a concentration of $8 \%$. In the groups exposed to arginine, the dentin specimens were immersed in the arginine solution for 5 minutes. For the groups with previous acid conditioning, the application of the $8 \%$ arginine solution was performed after the conditioning of the substrate. After 5 minutes of contact with the solution, the excess solution was removed from the dentin with an absorbent paper. Specimens restored without arginine pretreatment were considered the conventional technique. The $n=12$ was established for each group and information about adhesive systems and techniques are presented in - Table $\mathbf{1}$.

\section{Adhesive Protocols}

For each specimen, two resin composite pillars were made. The delimitations of the adhesive areas were performed with perforated adhesive tape (Vulcan, Colégio, Brazil) in the same dimensions of the matrix made using a perforated noodle. ${ }^{27}$ The adhesive systems were applied following the recommendations of the manufacturers (-Table 1). The matrix of perforated noodles (Furadinho 6 Pastifício Santa Amália, São Paulo, Brazil), $1 \mathrm{~mm}$ in height and $1.15 \mathrm{~mm}$ in internal diameter, was positioned, and then the adhesive was photoactivated for 10 seconds. The matrices were filled with flow resin (Z350 XT A2, 3M ESPE; Filtek, Sumaré, Brazil). The photoactivation was done with the third-generation LED source Valo (Ultradent; Indaiatuba, Brazil) in high power mode for 20 seconds that has an irradiance of $1400 \mathrm{~mW} / \mathrm{cm}^{2}$. The specimens were previously stored for 1 hour in distilled water to remove the noodle matrices.

\section{Microshear Strength Test}

After the storage in deionized water (24 hours or 6 months), the microshear test was performed with the universal testing machine EZ Test-L (Shimadzu Corporation, Tokyo, Japan) at a speed of $0.5 \mathrm{~mm} / \mathrm{min}$. The microshear BS results were given in megapascals (MPa) after measuring the bonding area using a digital caliper, according to the following formula: $R=$ rupture force $(\mathrm{Kgf}) \times 9.8 /$ area $\left(\mathrm{mm}^{2}\right)$, where $R$ is the BS in MPa.

\section{Fracture Pattern Analysis}

After the microshear test, the fracture pattern was categorized as (1) cohesive in dentin, (2) adhesive, (3) cohesive in resin, or (4) mixed. For this, a stereoscopic magnifying glass was used (MZ75; Leica Microsystems, Heerbrugg, Switzerland) at $100 \times$ magnification. 
Table 1 Recommendation of manufacturers for each adhesive system and description of the arginine pretreatment

\begin{tabular}{|c|c|c|}
\hline $\begin{array}{l}\text { Adhesive } \\
\text { system }\end{array}$ & Manufacturer & Recommendations for use \\
\hline $\begin{array}{l}\text { Scotch- } \\
\text { bond } \\
\text { multi- } \\
\text { purpose } \\
\text { (SBMP) }\end{array}$ & 3M ESPE & $\begin{array}{l}\text { Preliminary acid conditioning } \\
\text { with } 35 \% \text { phosphoric acid for } \\
15 \text { seconds. Flush with water } \\
\text { for } 10 \text { seconds. Removal of } \\
\text { the water excess with a light } \\
\text { jet of air. Apply the primer and } \\
\text { dry with a light jet of air for } \\
5 \text { seconds. Apply the bond, } \\
\text { drying with a light jet of air for } \\
5 \text { seconds and photoactivation } \\
\text { for } 10 \text { seconds }\end{array}$ \\
\hline $\begin{array}{l}\text { Single } \\
\text { bond } \\
\text { (SB) }\end{array}$ & 3M ESPE & $\begin{array}{l}\text { Apply } 35 \% \text { phosphoric acid } \\
\text { (3M ESPE) for } 15 \text { seconds on } \\
\text { the dentin surface. Wash the } \\
\text { surface for } 10 \text { seconds and dry } \\
\text { with absorbent paper. Apply } \\
\text { two layers of the adhesive. } \\
\text { Drying of the surface with a } \\
\text { light jet of air for } 5 \text { seconds } \\
\text { and photoactivation of the } \\
\text { system for } 10 \text { seconds }\end{array}$ \\
\hline $\begin{array}{l}\text { Clearfil } \\
\text { SE bond } \\
(C S E B)\end{array}$ & Kuraray & $\begin{array}{l}\text { Apply acid primer for } \\
20 \text { seconds. Dry with a light } \\
\text { jet of air. Afterward apply } \\
\text { bond, drying with light air } \\
\text { jet and photoactivation for } \\
10 \text { seconds }\end{array}$ \\
\hline $\begin{array}{l}\text { Conven- } \\
\text { tional } \\
\text { technique } \\
\text { (C) }\end{array}$ & - & $\begin{array}{l}\text { No dentin pretreatment other } \\
\text { than that specified by the } \\
\text { manufacturers }\end{array}$ \\
\hline $\begin{array}{l}\text { Arginine } \\
\text { pretreat- } \\
\text { ment }(A)\end{array}$ & - & $\begin{array}{l}\text { Contact with } 8 \% \text { arginine solu- } \\
\text { tion for } 5 \text { minutes prior to res- } \\
\text { toration, at room temperature }\end{array}$ \\
\hline
\end{tabular}

Abbreviations: CSEB, Clearfil SE Bond (Kuraray); SB, Single Bond 2 (3M ESPE); SBMP, Scotchbond multipurpose (3M ESPE); A, 8\% arginine pretreatment.

\section{Scanning Electron Microscopy}

Three specimens of each group were randomly made to obtain the images of dentin morphology by scanning electron microscope (JSM 5600 LV; JEOL, Tokyo, Japan). Images were obtained representing dentin (A), dentin exposed to arginine (B), dentin conditioned with $37 \%$ phosphoric acid (C), and dentin conditioned with $37 \%$ phosphoric acid and exposed to arginine (D). These specimens were fixed separately on acrylic discs and properly prepared for the analysis with a layer of gold palladium and then evaluated at a magnification of $2000 \times$ and $4000 \times$.

\section{Statistical Analysis}

The results of immediate and long-term microshear tests were initially investigated using a Shapiro-Wilk test. Immediate microshear data were submitted to a two-way analysis of variance and Tukey's test. The long-term microshear data were evaluated by Kruskal-Wallis and Dunn tests. The level of significance was set at $5 \%$.

\section{Results}

- Table 2 presents the results of the microshear test (Mpa) for the immediate BS. The statistical analysis showed an effect on the following factors: treatment/presence of arginine $(p<0.0001)$, adhesive system $(p<0.0001)$, and the interaction between them $(p<0.001)$. The conventional technique groups did not show statistical difference between them $(p>0.05)$. Also, the Scotchbond Multipurpose (3M ESPE) (SBMP) control group did not differ statistically from the SBMP group previously exposed to arginine $(p>0.05)$. For Single Bond 2 (3M ESPE) (SB) and Clearfil SE Bond (Kuraray) (CSEB), there was a statistical difference between the conventional technique groups compared with arginine pretreatment for both adhesive systems, presenting lower values of BS $(p<0.05)$. The data obtained from the analysis of the immediate fracture pattern were analyzed by the frequency distribution in percentage (-Fig. 1). It is possible to observe an increase and predominance of the adhesive failure pattern in the groups that received the pretreatment with arginine solution, corroborating the results found for the BS. Comparison of the adhesive failure pattern of conventional technique groups and arginine groups showed that SMBP went from 25 to $46 \%$, SB from 63 to $96 \%$ and CSEB from 21 to $92 \%$.

- Table 3 showed the results of the long-term microshear values (Mpa) after 6 months of water storage. The results of the Kruskal-Wallis and Dunn tests showed no statistical difference between the groups that underwent the conventional adhesive technique $(p>0.05)$. The SBMP control group did not differ statistically from the specimens previously treated

Table 2 Means (standard deviation) of the microshear values (MPa) of immediate bond strength $(n=12)^{\text {a }}$

\begin{tabular}{|l|l|l|}
\hline \multirow{2}{*}{$\begin{array}{l}\text { Adhesive } \\
\text { system }\end{array}$} & \multicolumn{2}{|c|}{ Technique } \\
\cline { 2 - 3 } & Conventional & \multicolumn{1}{|c|}{ Arginine pretreatment } \\
\hline SBMP & $11.1(4.2) \mathrm{Aa}$ & $13.4(2.7) \mathrm{Aa}$ \\
\hline SB & $11.4(3.1) \mathrm{Aa}$ & $5.4(3.2) \mathrm{Bb}$ \\
\hline CSEB & $11.2(2.9) \mathrm{Aa}$ & $4.0(1.0) \mathrm{Bb}$ \\
\hline
\end{tabular}

Abbreviations: CSEB, Clearfil SE Bond (Kuraray); SB, Single Bond 2 (3M ESPE); SBMP, Scotchbond multipurpose (3M ESPE).

aMeans (standard deviation) followed by distinct letters (uppercase in rows and lowercase in columns) are statistically different $(p<0.05)$.

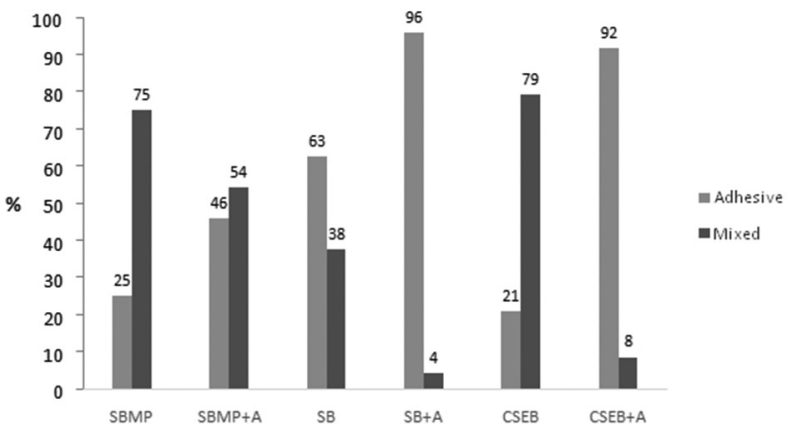

Fig. 1 Analysis of the immediate fracture pattern (\%) with the percentage of adhesive and mixed failures. A, $8 \%$ arginine pretreatment; CSEB, Clearfil SE Bond (Kuraray); SB, Single Bond 2 (3M ESPE); SBMP, Scotchbond Multipurpose (3M ESPE). 
Table 3 Median (minimum; maximum) of the microshear values (MPa) of 6-month bond strength $(n=12)$

\begin{tabular}{|l|l|l|}
\hline \multirow{2}{*}{ Adhesive system } & \multicolumn{2}{|c|}{ Technique } \\
\cline { 2 - 3 } & \multicolumn{1}{|c|}{ Conventional } & \multicolumn{1}{|c|}{$\begin{array}{c}\text { Arginine } \\
\text { pretreatment }\end{array}$} \\
\hline SBMP & $\begin{array}{l}12.5(6.8 ; 19.6) \\
\mathrm{Aa}\end{array}$ & $12.2(6.4 ; 19.1) \mathrm{Aa}$ \\
\hline SB & $\begin{array}{l}9.8(1.1 ; 18.7) \\
\mathrm{Aa}\end{array}$ & $0.6(0 ; 12) \mathrm{Bb}$ \\
\hline CSEB & $\begin{array}{l}8.9(4.7 ; 18.3) \\
\mathrm{Aa}\end{array}$ & $2.7(1.4 ; 3.7) \mathrm{Bb}$ \\
\hline
\end{tabular}

Abbreviations: CSEB, Clearfil SE Bond (Kuraray); SB, Single Bond 2 (3M ESPE); SBMP, Scotchbond multipurpose (3M ESPE).

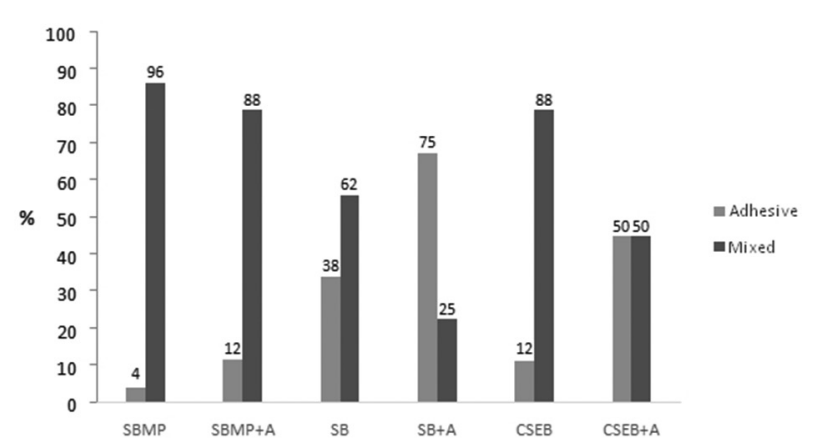

Fig. 2 Analysis of the fracture pattern (\%) after water aging for 6 months. CSEB, Clearfil SE Bond (Kuraray); SB, Single Bond 2 (3M ESPE); SBMP, Scotchbond multipurpose (3M ESPE); A, 8\% arginine pretreatment. with arginine $(p>0.05)$. For SB and CSEB, the pretreatment with $8 \%$ arginine solution interfered negatively in the BS for these adhesive systems, presenting results that differ statistically from the respective control groups, restored using the conventional technique $(p<0.05)$. The fracture pattern after 6 months of water aging ( $\mathbf{- F i g . ~ 2 )}$ ) was analyzed by the frequency distribution in percentage. The results demonstrate an increase in the adhesive failure pattern in the groups that received the pretreatment with $8 \%$ arginine solution, corroborating the results found for the BS. Comparison of the adhesive failure pattern of conventional technique groups and arginine groups indicated the following: SMBP went from 4 to $13 \%$, SB from 38 to $75 \%$, and CSEB from 13 to $50 \%$. After 6 months of water aging, a few samples experienced catastrophic adhesive failure represented by the loss of resin pillar. The control SBMP group lost four pillars, while SBMP exposed to arginine did not lose any pillars. SB lost 5 pillars and CSEB lost 1 when they were exposed to arginine pretreatment, $\mathrm{SB}+\mathrm{A}$ losses increased to 16 , and $\mathrm{CSEB}+\mathrm{A}$ to 8 .

The images obtained by SEM ( - Figs. 3 and $\mathbf{4}$ ) demonstrate a different conditioning pattern for the groups previously exposed to the $8 \%$ arginine solution, with greater preservation of the intertubular dentin (sets) and an increase in the diameter of the dentinal tubules (dotted line) and intertubular distance (continuous line).

\section{Discussion}

Based on the results of this study, the null hypothesis was partially rejected because an interaction of arginine in the
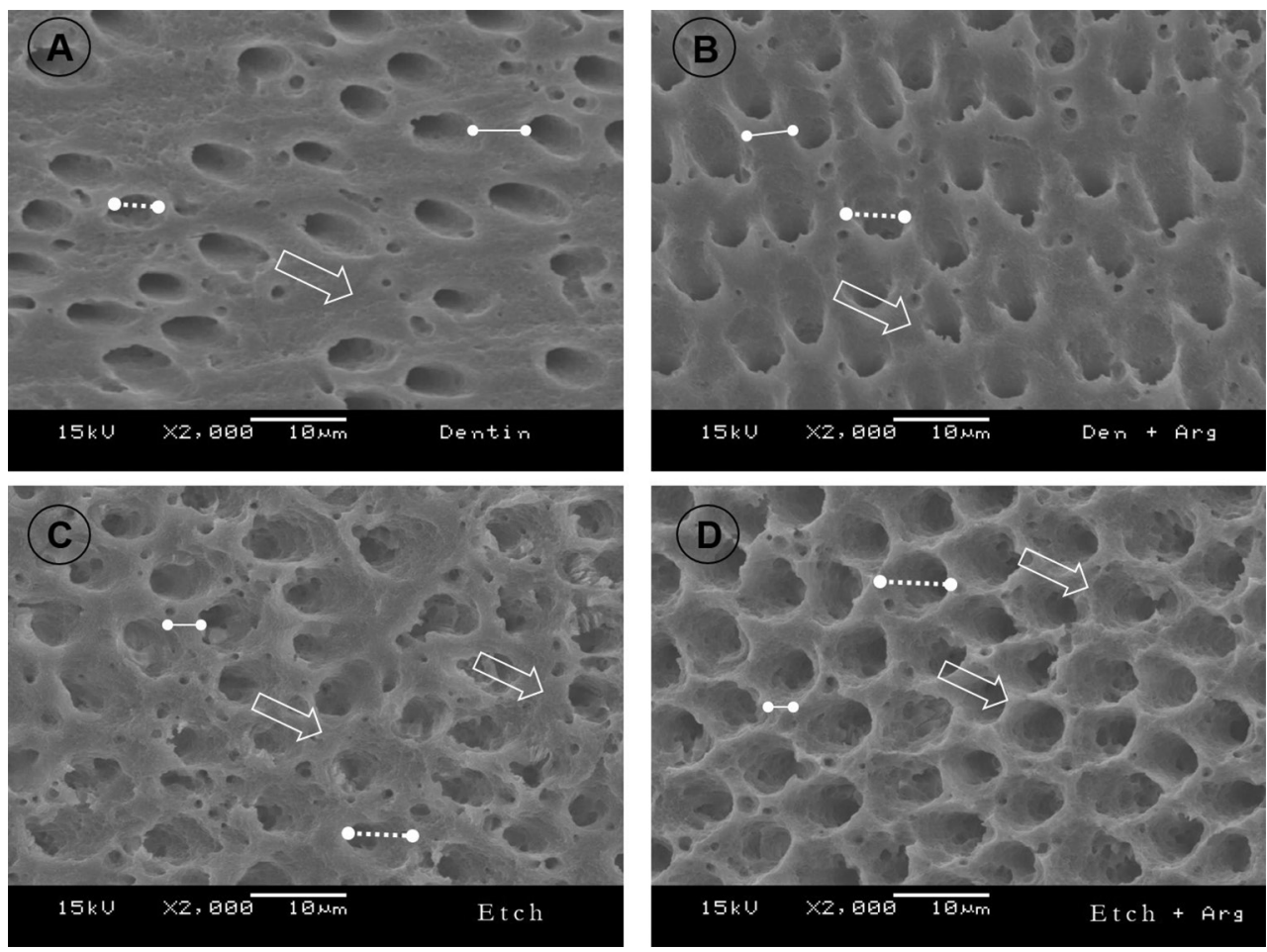

Fig. 3 Representative images obtained by scanning electron microscopy at a magnification of 2000x. The sets indicate intertubular dentin, the dotted lines represent the diameter of the dentinal tubules, and the continuous lines demonstrate the intertubular distance. 

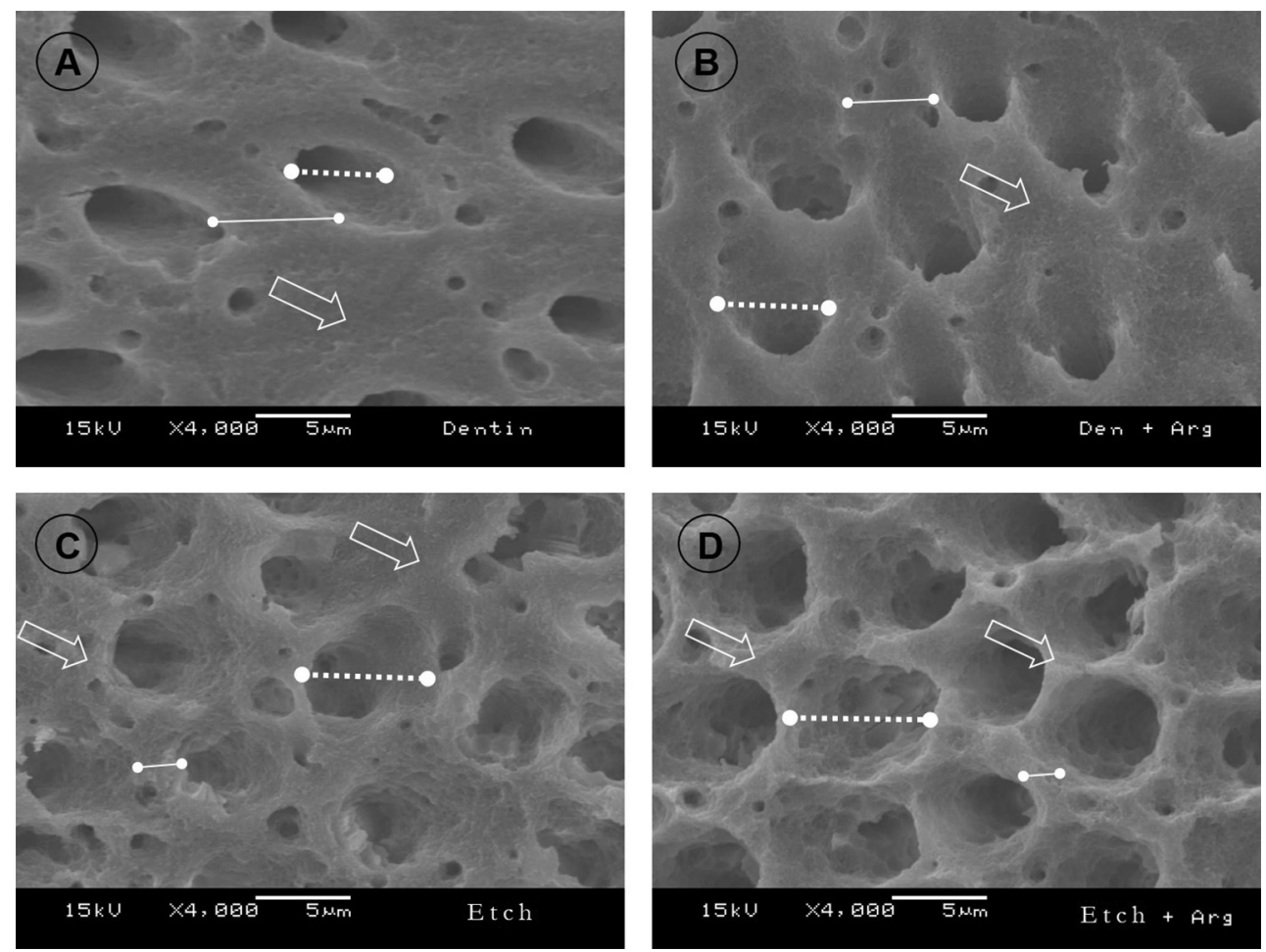

Fig. 4 Representative images obtained by scanning electron microscopy at a magnification of 4000x. The sets indicate intertubular dentin, the dotted lines represent the diameter of the dentinal tubules, and the continuous lines demonstrate the intertubular distance.

adhesion process of SB and CSEB was found; however, the arginine did not affect the SBMP BS. Adhesive restorative treatments are procedures performed daily by dentists. The adhesive techniques are critical and require several cautions to succeed, such as humidity control and avoiding contamination of the operative field. ${ }^{28}$ Such factors are directly related to the longevity of the restorative treatments because the main cause of adhesive failure is marginal infiltration and consequently biofilm retention and the development of caries over time. ${ }^{29}$ The adhesion on enamel is established, and the challenge is related to the dentin adhesion that presents a complex structural composition. ${ }^{30}$

The success of direct restorations is impaired by the adhesion and the hybrid layer degradation, ${ }^{6}$ which are mainly caused by the hydrolysis of the composites and the collagen fibrils that interact with the adhesive system., ${ }^{2,3}$ These collagen fibrils become vulnerable to degradation by the activation of the MMPs and the cysteine cathepsins, ${ }^{1,31}$ as well as in the presence of microleakages in the restoration mainly caused by the mechanical and hydraulic fatigue. ${ }^{4,31}$ In the present study, despite the arginine pretreatment acting positively over the dentin surface, for simplified adhesives, the arginine interfered negatively over the adhesion of the resin composite on dentin and also increased the percentages of adhesive failure for all adhesive systems. The long-term specimens also experienced a catastrophic adhesive failure, where a percentage of resin composite pillars was lost during the water storage.

Nowadays, researchers are focusing on the development of surface treatments that promote an increase in adhesion or a decrease in hybrid layer degradation. ${ }^{1,6,31}$ Wang et $\mathrm{al}^{32}$ suggested that toothpaste containing arginine-calcium carbonate did not negatively affect the bonding capacity of different adhesive systems, although its use enables occlusion of the dentinal tubules, which could have benefits in the prevention of postoperative sensitivity. Furthermore, an in-office desensitizing paste containing arginine and calcium carbonate did not affect the enamel adhesion. ${ }^{20}$ Another investigation ${ }^{33}$ evaluated the effect of desensitizing toothpaste with arginine on the dentin and found no interference in the adhesion.

Moreover, Aguiar et al ${ }^{34}$ described that the extended use of conventional or arginine-calcium carbonate toothpaste did not interfere with the dentin BS when a 2-step self-etch adhesive was used; however, it can produce an increase in the hardness and roughness of the dentin substrate. Corroborating with other studies, Yang et $\mathrm{al}^{35}$ reported that arginine-calcium carbonate paste applied after etching can achieve effective tubule occlusion without affecting the adhesion.

A previous study ${ }^{19}$ evaluated the effect of three dentifrices containing calcium on the adhesive capacity of two self-etch adhesive systems, demonstrating that the adhesive systems are capable of interacting with the calcium present in toothpastes, mainly self-etch adhesives that include in their composition the MDP monomer. Thus, despite the satisfactory results of arginine/calcium carbonate products on enamel and dentin adhesion described by these different authors, the findings of the present study indicate that the sole use of arginine would not be beneficial. However, it is not possible to make direct comparisons with the results of the present study and commercial products with arginine, which is usually commercially available as an arginine-calcium 
carbonate complex. The calcium carbonate possibly promotes a mutualistic complex with arginine when incorporated in commercial products, whereas in the present study, the sole arginine acted negatively in the dentin adhesion of simplified adhesive systems. To verify the effect of arginine pretreatment established adhesive systems in adhesion science were selected, Scotchbond Multipurpose (3M ESPE) and Clearfil SE Bond (Kuraray), and other system commonly used around the world, such as Single Bond 2 (3M ESPE). However, new studies can be performed to test a universal/multimode adhesive system because it has a differentiated composition with monomers that produce chemical and micromechanical adhesion to the dental hard tissue, ${ }^{36}$ which could chemically relate to the arginine-dentin complex.

Arginine is a basic amino acid, stable in aqueous solution and capable of alkalinizing the local $\mathrm{pH} .{ }^{22}$ Based on the mechanism described by Kleinberg, ${ }^{37}$ arginine is attracted to negatively charged dentin, promoting precipitation of calcium and phosphate in the entrance of the dental tubules present in toothpaste and saliva. The images obtained by SEM (-Fig. 3) showed a preservation of the intertubular dentin, probably because of the interaction of the arginine with the dentin or collagen fibrils. Considering the characteristics of arginine, initially was hypothesized a benefit of dental adhesion and action on collagen fibrils or MMPs; however, based on the results (-Tables 2 and 3 ), this hypothesis was rejected. Arginine is a soluble and unstable molecule in acid $\mathrm{pH},{ }^{38-40}$ and single-bottle adhesives (SB) and self-etch adhesives (CSEB) present low $\mathrm{pH}^{41}$ and the application of these adhesive systems after pretreatment of dentin surface with $8 \%$ arginine can promote the dissolution of precipitate formed by the interaction of the arginine and dental substrate, reducing the BS for these adhesive systems. No differences were found for BS when SBMP associated with arginine pretreatment; these results show a potential use of arginine for SBMP, and could in future be evaluated with other storage times and characterizations of the MMPs activity or collagen fibril architecture/network to validate a potential as MMP inhibitor.

In the present study, the application of solution for $5 \mathrm{~min}$ utes was used based on previous studies ${ }^{42,43}$ that applied other agents in a similar time, determining a potential effect of different compounds. However, future investigations could evaluate the behavior of agents with other application times, examine their use associated with other adhesive systems, or compare them with other agents already used for this purpose, such as chlorhexidine. Montagner et $\mathrm{al}^{44}$ state that chlorhexidine is the more used MMP inhibitor in the literature and does not affect the immediate BS; however, it promotes an increase in long-term BS, unlike the results of the present study for arginine. Moreover, this meta-analysis showed high heterogeneity in some comparisons, especially for condition of water storage. Water storage is a way to accelerate the degradation process of the hybrid layer because the water contact with the unprotected collagen fibrils after the application of the adhesive system stimulates the degradation of the hybrid layer. ${ }^{45}$ The water acts to remove/ leach residual solvents from the adhesive system after the photopolymerization. ${ }^{46}$ Artificial aging enables evaluation of the longevity of the restorative procedure and is usually associated with lower values of BS. ${ }^{47}$ In vitro protocols for adhesion analysis are important precursors to clinical practice; however, more studies are necessary to better understand this adhesion mechanism and the arginine interaction with the dental structure.

\section{Conclusion}

The dentin pretreatment with arginine interfered negatively in the adhesion of simplified adhesive systems. However, the 3-step etch-and-rinse adhesive was not affected by arginine pretreatment presenting the most satisfactory results.

\section{Funding}

This study was financed in part by the Coordenação de Aperfeiçoamento de Pessoal de Nível Superior - Brasil (CAPES) - Finance Code 001.

\section{Conflict of Interest}

None declared.

\section{References}

1 Perdigão J, Reis A, Loguercio AD. Dentin adhesion and MMPs: a comprehensive review. J Esthet Restor Dent 2013;25(4):219-241

2 Ito S, Hashimoto M, Wadgaonkar B, et al. Effects of resin hydrophilicity on water sorption and changes in modulus of elasticity. Biomaterials 2005;26(33):6449-6459

3 Chiaraputt S, Mai S, Huffman BP, et al. Changes in resin-infiltrated dentin stiffness after water storage. J Dent Res 2008;87(7):655-660

4 Toledano M, Osorio R, Osorio E, et al. Effect of bacterial collagenase on resin-dentin bonds degradation. J Mater Sci Mater Med 2007;18(12):2355-2361

5 Okuda M, Pereira PN, Nakajima M, Tagami J. Relationship between nanoleakage and long-term durability of dentin bonds. Oper Dent 2001;26(5):482-490

6 Frassetto A, Breschi L, Turco G, et al. Mechanisms of degradation of the hybrid layer in adhesive dentistry and therapeutic agents to improve bond durability---a literature review. Dent Mater 2016;32(2):e41-e53

7 Tjäderhane L, Larjava H, Sorsa T, Uitto VJ, Larmas M, Salo T. The activation and function of host matrix metalloproteinases in dentin matrix breakdown in caries lesions. J Dent Res 1998;77(8):1622-1629

8 Chaussain-Miller C, Fioretti F, Goldberg M. Menashi S. The role of matrix metalloproteinases (MMPs) in human caries. J Dent Res 2006;85(1):22-32

9 Pashley DH, Tay FR, Yiu C, et al. Collagen degradation by host-derived enzymes during aging. J Dent Res 2004;83(3):216-221

10 Carrilho MR, Tay FR, Donnelly AM, et al. Host-derived loss of dentin matrix stiffness associated with solubilization of collagen. J Biomed Mater Res B Appl Biomater 2009;90(1):373-380

11 Perumal S, Antipova O, Orgel JP. Collagen fibril architecture, domain organization, and triple-helical conformation govern its proteolysis. Proc Natl Acad Sci U S A 2008;105(8):2824-2829

12 Wang Y, Spencer P. Quantifying adhesive penetration in adhesive/dentin interface using confocal Raman microspectroscopy. J Biomed Mater Res 2002;59(1):46-55

13 Wang Y, Spencer P. Hybridization efficiency of the adhesive/dentin interface with wet bonding. J Dent Res 2003;82(2):141-145 
14 Breschi L, Mazzoni A, Nato F, et al. Chlorhexidine stabilizes the adhesive interface: a 2-year in vitro study. Dent Mater 2010;26(4):320-325

15 De Munck J, Van den Steen PE, Mine A, et al. Inhibition of enzymatic degradation of adhesive-dentin interfaces. J Dent Res 2009;88(12):1101-1106

16 Nassar M, Hiraishi N, Shimokawa H, et al. The inhibition effect of non-protein thiols on dentinal matrix metalloproteinase activity and HEMA cytotoxicity. J Dent 2014;42(3):312-318

17 Breschi L, Martin P, Mazzoni A, et al. Use of a specific MMP-inhibitor (galardin) for preservation of hybrid layer. Dent Mater 2010;26(6):571-578

18 Carrilho MR, Geraldeli S, Tay F, et al. In vivo preservation of the hybrid layer by chlorhexidine. J Dent Res 2007;86(6):529-533

19 Pei D, Liu S, Huang C, et al. Effect of pretreatment with calcium-containing desensitizer on the dentine bonding of mild self-etch adhesives. Eur J Oral Sci 2013;121(3 Pt 1) :204-210

20 García-Godoy A, García-Godoy F. Effect of an $8.0 \%$ arginine and calcium carbonate in-office desensitizing paste on the shear bond strength of composites to human dental enamel. Am J Dent 2010;23(6):324-326

21 Kolker JL, Vargas MA, Armstrong SR, Dawson DV. Effect of desensitizing agents on dentin permeability and dentin tubule occlusion. J Adhes Dent 2002;4(3):211-221

22 Zaloga GP, Siddiqui R, Terry C, Marik PE. Arginine: mediator or modulator of sepsis? Nutr Clin Pract 2004;19(3):201-215

23 Hamlin D, Williams KP, Delgado E, Zhang YP, DeVizio W, Mateo LR. Clinical evaluation of the efficacy of a desensitizing paste containing $8 \%$ arginine and calcium carbonate for the in-office relief of dentin hypersensitivity associated with dental prophylaxis. Am J Dent 200922 Spec No A:16A-20A

24 Schiff T, Delgado E, Zhang YP, Cummins D, DeVizio W, Mateo LR. Clinical evaluation of the efficacy of an in-office desensitizing paste containing $8 \%$ arginine and calcium carbonate in providing instant and lasting relief of dentin hypersensitivity. Am J Dent 200922 Spec No A:8A-15A

25 Souza ML, Cury JA, Tenuta LM, et al. Comparing the efficacy of a dentifrice containing $1.5 \%$ arginine and $1450 \mathrm{ppm}$ fluoride to a dentifrice containing $1450 \mathrm{ppm}$ fluoride alone in the management of primary root caries. J Dent 2013;41Suppl 2 :S35-S41

26 Vieira-Junior WF, Ferraz LN, Pini N, et al. Effect of toothpaste use against mineral loss promoted by dental bleaching. Oper Dent 2018;43(2):190-200

27 Vieira HH, Catelan A, Lima DANL, et al. Influence of matrix type on microshear bond strength test. Dent Cadmos 2016;84:314-318

28 Nair P, Hickel R, Ilie N. Adverse effects of salivary contamination for adhesives in restorative dentistry. A literature review. Am J Dent 2017;30(3):156-164

29 Hickel R, Manhart J. Longevity of restorations in posterior teeth and reasons for failure. J Adhes Dent 2001;3(1):45-64

30 Van Meerbeek B, De Munck J, Yoshida Y, et al. Adhesion to enamel and dentin: currents status and future challenges. Oper Dent 2003;28:215-235

31 Tjäderhane L, Nascimento FD, Breschi L, et al. Optimizing dentin bond durability: control of collagen degradation by matrix metalloproteinases and cysteine cathepsins. Dent Mater 2013;29(1):116-135
32 Wang Y, Liu S, Pei D, Du X, Ouyang X, Huang C. Effect of an 8.0\% arginine and calcium carbonate in-office desensitizing paste on the microtensile bond strength of self-etching dental adhesives to human dentin. Am J Dent 2012;25(5):281-286

33 Canares G, Salgado T, Pines MS, Wolff MS. Effect of an $8.0 \%$ arginine and calcium carbonate desensitizing toothpaste on shear dentin bond strength. J Clin Dent 2012;23(2):68-70

34 Aguiar JD, Medeiros IS, Souza Junior MHSE, Loretto SC. Influence of the extended use of desensitizing toothpastes on dentin bonding, microhardness and roughness. Braz Dent J 2017;28(3):346-353

35 Yang H, Pei D, Chen Z, Lei J, Zhou L, Huang C. Effects of the application sequence of calcium-containing desensitising pastes during etch-and-rinse adhesive restoration. J Dent 2014;42(9):1115-1123

36 Hanabusa M, Mine A, Kuboki T, et al. Bonding effectiveness of a new 'multi-mode' adhesive to enamel and dentine. J Dent 2012;40(6):475-484

37 Kleinberg I. SensiStat. A new saliva-based composition for simple and effective treatment of dentinal sensitivity pain. Dent Today 2002;21(12):42-47

38 Parkinson CR, Willson RJ. A comparative in vitro study investigating the occlusion and mineralization properties of commercial toothpastes in a four-day dentin disc model. J Clin Dent 2011;22(3):74-81

39 Parkinson CR, Willson RJ. An in vitro investigation of two currently marketed dentin tubule occlusion dentifrices. J Clin Dent 2011;22(1):6-10

40 Vieira-Junior WF, Lima DA, Tabchoury CP, Ambrosano GM, Aguiar FH, Lovadino JR. Effect of toothpaste application prior to dental bleaching on whitening effectiveness and enamel properties. Oper Dent 2016;41(1):E29-E38

41 Hipólito VD, Alonso RC, Carrilho MR, Anauate Netto C, Sinhoreti MA, Goes MF. Microtensile bond strength test and failure analysis to assess bonding characteristics of different adhesion approaches to ground versus unground enamel. Braz Dent J 2011;22(2):122-128

42 Thompson JM, Agee K, Sidow SJ, et al. Inhibition of endogenous dentin matrix metalloproteinases by ethylenediaminetetraacetic acid. J Endod 2012;38(1):62-65

43 Trindade TF, Barbosa AFS, Castro-Raucci LMS, Silva-Sousa YTC, Colucci V, Raucci-Neto W. Chlorhexidine and proanthocyanidin enhance the long-term bond strength of resin-based endodontic sealer. Braz Oral Res 2018;32:e44

44 Montagner AF, Sarkis-Onofre R, Pereira-Cenci T. Cenci MS. MMP inhibitors on dentin stability: a systematic review and meta-analysis. J Dent Res 2014;93(8):733-743

45 Liu Y, Tjäderhane L, Breschi L, et al. Limitations in bonding to dentin and experimental strategies to prevent bond degradation. J Dent Res 2011;90(8):953-968

46 Amaral FL, Colucci V, Palma-Dibb RG, Corona SA. Assessment of in vitro methods used to promote adhesive interface degradation: a critical review. J Esthet Restor Dent 2007;19(6):340-353,discussion354

47 Breschi L, Mazzoni A, Ruggeri A. Cadenaro M, Di Lenarda R, De Stefano Dorigo E. Dental adhesion review: aging and stability of the bonded interface. Dent Mater 2008;24(1):90-101 